www.nature.com/ejhg

\title{
An essential SMN interacting protein (SIP1) is not involved in the phenotypic variability of spinal muscular atrophy (SMA)
}

\author{
C Helmken ${ }^{1}$, A Wetter ${ }^{1}$, S Rudnik-Schöneborn ${ }^{2}$, T Liehr $^{3}$, K Zerres $^{2}$ and B Wirth ${ }^{1}$ \\ ${ }^{1}$ Institute of Human Genetics, Bonn; ${ }^{2}$ Institute of Human Genetics, Aachen; ${ }^{3}$ Institute of Human Genetics and \\ Anthropology, Jena, Germany
}

The survival motor neuron (SMN) protein and the SMN interacting protein 1 (SIP1) are part of a $300 \mathrm{kD}$ protein complex with a crucial role in snRNP biogenesis and pre-mRNA splicing. Both proteins are colocalised in nuclear structures called gems and in the cytoplasm. Approximately $96 \%$ of patients with autosomal recessive spinal muscular atrophy (SMA) show mutations in the SMN1 gene, while about $4 \%$ fail to show any mutation, despite a typical SMA phenotype. Additionally, sibs with identical $5 q 13$ homologs and homozygous absence of SMN1 can show variable phenotypes which suggest that SMA is modified by other, yet unknown factors. Since both genes, SMN1 and SIP1, belong to the same pathway and are part of the same protein complex, it is obvious to ask whether mutations within SIP1 are responsible for both the phenotypic variability and the appearance of non-SMN mutated SMA patients. First, we identified the chromosomal location of SIP1 and assigned it to chromosomal region 14q13-q21 by fluorescence in situ hybridisation. No SMA related disorder has yet been assigned to this chromosomal region. Next, we determined the exon-intron structure of the SIP1 gene which encompasses 10 exons and identified five transcription isoforms. We sequenced either RT-PCR products or genomic DNA covering the complete coding region from 23 typical SMA patients who had failed to show any SMN1 mutation. No mutation and no polymorphism was found within SIP1. Additionally, we sequenced RT-PCR products or genomic fragments of the entire SIP1 coding region from 26 sibs of 11 SMA families with identical genotypes ( $\triangle 7 \mathrm{SMN} / \triangle 7 \mathrm{SMN}$ or $\triangle 7 \mathrm{SMN}$ / other mutation) but different phenotypes and again no mutation was found. Finally, we performed quantitative analysis of RT-PCR products from the same 26 sibs. No difference in expression level of the five isoforms among phenotypically variable sibs was observed. Based on these data, we suggest that neither the phenotypic variability nor the 5q-unlinked SMA are caused by mutations within SIP1. European Journal of Human Genetics (2000) 8, 493-499.

Keywords: SMN interacting protein 1 (SIP1); survival motor neuron gene (SM N 1); spinal muscular atrophy (SMA); genomic structure; physical location; molecular analysis; neuromuscular disease; mutation analysis

\section{Introduction}

Autosomal recessive spinal muscular atrophy (SMA) is a neuromuscular disorder with an incidence of 1:6000 to $1: 10000 .^{1,2}$ SMA is characterised by atrophy and muscle weakness of voluntary muscles. Three types of SMA (TypesI-

Correspondence: PD Dr Brunhilde Wirth, Institute of Human Genetics, Wilhelmstrasse 31, 53111 Bonn, Germany. Tel: +49228 2872344; Fax: +49 228 2872380; E-mail: bwirth@uni-bonn.de

Received 22 November 1999; revised 18 January 2000; accepted

21 January 2000
III) have been defined based on age of onset and achieved motor milestones. ${ }^{3}$ In most families, there is a high degree of similarity between the clinical picture of affected sibs. ${ }^{4}$ Nevertheless, there are quite a few reports in which large phenotypic variability has been described among sibs with identical $5 q 13$ homologs. ${ }^{5-8}$ The main SMA determining gene is the survival motor neuron gene (SMN 1) which in SMA patients is mutated in about $96 \% .^{9-11}$ Of the $5 q 13$-linked SMA patients, $96.4 \%$ show homozygous absence of SMN 1 exons 7 and 8 or exon 7 only, whereas $3.6 \%$ present a 
compound heterozygosity with a subtle mutation on one chromosome and a deletion/gene conversion on the other chromosome. ${ }^{10}$ The severity of SMA is strongly influenced by SM N2, a highly homologous copy of SMN 1. The more SM N2 copies a patient has, the milder is the SMA phenotype. ${ }^{11-14}$ The explanation for this effect is based on a single nucleotide difference in exon 7 of SMN1 compared with SMN2 which leads to alternative splicing and disruption of a putative exonic splicing enhancer. ${ }^{15}$ None of the polymorphisms recently reported within intron 6 are responsible for the alternative splicing. ${ }^{16}$ Whilst SMN 1 produces only full length transcript, SM N2 mainly produces alternatively spliced transcript. ${ }^{9,15,17}$ Furthermore, it has been shown that exon 7 is part of a domain responsible for the oligomerisation of the SMN protein, ${ }^{18}$ In other words, the protein produced by SMN2 is less efficient and its role can be partially compensated by an increased number of SMN2 copies.

About $4-5 \%$ of typical SMA patients showed by quantitative PCR analysis to have two SMN1 copies and no evident mutations, suggesting no linkage to $5 \mathrm{q} .{ }^{11}$

SMN is part of a 300-kD protein complex, in which SMN interacts with itself, SIP1 (SMN interacting protein 1), Sm proteins that are common components of spliceosomal snRNPs, and other, yet unknown components. ${ }^{19-21}$ SMN and SIP1 are co-localized in nuclear structures called gems and in the cytoplasm; both proteins are expressed in similar tissues. $^{19}$ The SIP1-CDNA of $1285 \mathrm{bp}$ encodes a protein of 279 amino acids, which binds to a distinct binding site at the $\mathrm{N}$-terminus (aa13-44) of SMN. This SMN-SIP1 complex has an essential function in spliceosomal snRNP-biogenesis (assembly and recycling of snRNPs) and in pre-mRNA splicing. ${ }^{20-22}$ It is therefore obvious to ask whether SIP1 influences the variability of the SMA phenotype or whether in patients who failed to show 5q-linked SMA the disease is caused by mutations within SIP1.

\section{Materials and methods Patient samples}

All patients fulfilled the diagnostic criteria for proximal spinal muscular atrophy defined by the International SMA Consortium ${ }^{3}$ and Zerres and Rudnik-Schöneborn. ${ }^{23}$ According to Zerres and Rudnik-Schöneborn ${ }^{23}$ typel SMA patients have an age of onset below 10 months and are never able to sit; typell SMA patients have an age of onset below 18 months and are unable to walk; typellla SMA patients have an age of onset <3years; and typelllb SMA patients $>3$ years, the latter showing a mild course with a high probability of remaining ambulant for decades. Informed consent was obtained from all subjects.

Twenty-three typical SMA patients (5 type1, 2 typell and 16 typellI), who did not show mutations in the SMN 1 gene and carried two SMN1 copies, have been previously described $^{11}$ and were now analysed for mutations in the SIP1 gene. From 14 patients (one typel, one typell and 12 typellI) permanent lymphoblastoid cell lines were available for RNA isolation. Additionally, lymphoblastoid cell lines from 26 sibs belonging to 11 families were available for molecular genetic analysis of SIP1. In each family sibs show identical haplotypes and identical SMN1 mutations on both chromosomes. One family has four sibs (two typellI SMA and two unaffected sibs); three families have three sibs each (one family with a typellla SMA and two unaffected sibs, the second family with a typellla and two typellIb SMA sibs, and the third family with a typell and two typellla SMA sibs); and seven families with two sibs each (three families with one typelll and one unaffected sib, one family with one typell and one typellla SMA sib, and three families with one typellla and one typelllb SMA sib).

\section{DNA isolation and haplotype analysis}

DNA was isolated from blood samples or permanent lymphoblastoid cell lines by the salting-out method. ${ }^{24}$ The multicopy polymorphic markers Ag1-CA ${ }^{25}$ and $C 212^{26}$ were used for haplotype analysis as previously described. ${ }^{27}$

\section{Human BAC library screening}

A human BAC library (CEPH human BAC library No.751, 46XX lymphoblastoid cell line ligated into pBELOBAC) was screened with radioactively labelled full length SIP1 CDNA. Hybridisation and scoring of positive si gnals were carried out according to the given recommendations of RZPD Berlin. The obtained BAC clone containing the complete SIP1 gene has the following reference: B869G2 (CEPHB751M03476Q3).

\section{Determination of the exon-intron structure of SIP1 by sequencing BAC B869G2}

BAC DNA was purified with the midiplasmid-kit (Qiagen, Hilden, Germany). 800ng of DNA were used for cycle sequencing which was performed with BigDye Terminator Reaction Kit (PE Applied Biosystems, Weiterstadt, Germany) and primers derived from the SIP1 CDNA sequence. Sequencing was carried out on the automated $A B I 377$ A sequencer (Applied Biosystems).

Exon-intron structure was identified by sequence pair comparison between genomic and CDNA sequence of SIP1 using the BESTFIT program (HUSAR-Heidelberg). Primers were designed from each identified exon in both directions in order to determine the intronic flanking sequences.

\section{RNA isolation, RT-PCR and cloning of PCR products of SIP1}

RNA was isolated from Epstein-Barr virus transformed lymphoblastoid cell lines using Trizol kit (Life Technologies, Karlsruhe, Germany). First-strand cDNA synthesis was performed with oligo-dT primers, $4 \mu \mathrm{g}$ total RNA and M-MLV reverse transcriptase (Life Technologies) according to the manufacturer's instructions. The single-stranded cDNAs were 
amplified with $10 \mathrm{ng}$ of each primer SIP1-forward (5'-AGGTGTCTATTAGTGCGCCTG-3') within exon 1 and SIP1-reverse (5'-TGTTCATCAAAAACTGAGTGGG-3') within exon 10, $200 \mu \mathrm{m}$ each dNTP, $1 \cup$ Taq-polymerase (Life Technologies), $1.5 \mathrm{~mm} \mathrm{MgCl}_{2}$ within $50 \mu$ reaction volumes. PCR conditions included a $7 \mathrm{~min}$ initial denaturation at $94^{\circ} \mathrm{C}$ followed by $32 \mathrm{cycles}$ of $1 \mathrm{~min}$ at $94^{\circ} \mathrm{C}, 1 \mathrm{~min}$ at $58^{\circ} \mathrm{C}$ and $1.5 \mathrm{~min}$ at $72^{\circ} \mathrm{C}$, with a final extension of $7 \mathrm{~min}$ at $72^{\circ} \mathrm{C}$.

Since PCR of SIP1 CDNA revealed four faint fragments next to a strong full-length RT-PCR product, we assumed the existence of various alternatively spliced transcripts. These RT-PCR products were cloned into the PCRII-TOPO cloning vector (Invitrogen). $400 \mathrm{ng}$ of plasmid DNA were used for cycle sequencing.

For mutation analysis RT-PCR products were too faint and too large for direct sequencing. Therefore, $1 \mu \mathrm{l}$ of a 1:100 dilution of the first PCR product was reamplified with nested PCR primers. The SIP1 CDNA was subdivided into two pieces, $A$ and $B$, and amplified with the following primers: fragment A (584bp) with primers SIP1-nest:-a 5'-CGCTGTGACCTAGAATGG-3' flanking exon 1 and SIP1-nest-b: 5'-TGATTCATTCTGCTAACAATA-3' within exon 6 and fragment $B$ (259 bp) with the primers SIP1-nest-c: 5'-AGATGGCTTTATGCTITATTG-3' within exon 8 and SIP1-nest-d: 5'-GAGTTAGGCTGCCTTCATG-3' flanking exon 10. PCR conditions were as described for the first PCR reaction except the anneal ing temperature which was $54^{\circ} \mathrm{C}$.

Alternatively spliced exons6, 7 and 8 were analysed from genomic DNA (see below). Direct sequencing of RT-PCR products including these exons resulted in too high a background.

\section{PCR of genomic SIP1 exons}

From those patients where no RNA was available each exon was amplified from genomic DNA. Alternatively spliced exons6-8 were sequenced from genomic DNA from all patients. PCR reaction: 40 ng of genomic DNA was amplified using $10 \mathrm{pmol}$ of each primer (Table1) in a total volume of $25 \mu \mathrm{l}$ containing $200 \mu \mathrm{m}$ dNTPs, $1 \cup$ Taq-polymerase (Life Technologies) with $1.5 \mathrm{~mm} \mathrm{MgCl}_{2}$. Cycling conditions included a $1 \mathrm{~min}$ initial denaturation at $94^{\circ} \mathrm{C}$ followed by 32 cycles of $45 \mathrm{~s}$ at $94^{\circ} \mathrm{C}, 45 \mathrm{~s}$ at various temperatures (Table 1 ) and $45 \mathrm{~s}$ at $72^{\circ} \mathrm{C}$, with a final extension of $7 \mathrm{~min}$ at $72^{\circ} \mathrm{C}$. Cycle sequencing was carried out with $60 \mathrm{ng}$ DNA as described above.

Quantitative analysis of SIP1 transcription isoforms CDNAs were amplified in a total volume of $25 \mu$ l containing 10 pmol of each primer SIP1-5 forward (5'GCCAAAATCTGAAGATGAAG-3') within exon 5 and SIP1-9rev (5'-AACCAAGCAGATTAATAAATTC-3') within exon $9200 \mu \mathrm{m}$ dNTPs, $1 \mathrm{U}$ Taq-polymerase (Life Technologies) with $1.5 \mathrm{~mm} \mathrm{M} \mathrm{gCl}_{2}$. Cycling conditions include a $7 \mathrm{~min}$ initial denaturation at $94^{\circ} \mathrm{C}$ followed by 25 cycles of $30 \mathrm{~s}$ at $94^{\circ} \mathrm{C}, 30$ s at $54^{\circ} \mathrm{C}, 30 \mathrm{~s}$ at $72^{\circ} \mathrm{C}$ and a final extension of $7 \mathrm{~min}$ at $72^{\circ} \mathrm{C}$. The number of cycles was chosen in order to ensure linear amplification of PCR products.

PCR products were resolved on 10\% PAA gels and visualised by silver staining. ${ }^{6}$ Gels were $3 D$ scanned (BIORAD imaging system) and densitometric measurements were carried out with ONE-Dscan software (MWG, München, Germany). We evaluated the DNA ratio between each alternatively spliced isoform and the full length SIP1 transcript as well as the expression levels of each isoform among patients.

Table 1 Sequence of the PCR primers used for amplification of SIP1 genomic DNA

\begin{tabular}{|c|c|c|c|c|}
\hline Exon & Primer & Sequence & Length of PCR-product (bp) & Annealing-temp. $\left({ }^{\circ} \mathrm{C}\right)$ \\
\hline 1 & $\begin{array}{l}\text { SIP-Ex1-f } \\
\text { SIP-Ex1-r }\end{array}$ & $\begin{array}{l}\text { 5'-CGCTGTGACCTAGAATGG-3' } \\
\text { 5'-AATAGACCTGAACTCGCAAC-3' }\end{array}$ & 297 & 56 \\
\hline 2 & $\begin{array}{l}\text { SIP-EX2-f } \\
\text { SIP-EX2-r }\end{array}$ & $\begin{array}{l}\text { 5'-AAGTGGATCGCTTGTTITAC-3' } \\
\text { 5'-CGGAGTAGTCAAATCTTACG-3' }\end{array}$ & 274 & 54 \\
\hline 3 & $\begin{array}{l}\text { SIP-EX3-f } \\
\text { SIP-EX3-r }\end{array}$ & $\begin{array}{l}\text { 5'-CTGAATAAGAGCAGGGTATG-3' } \\
\text { 5'-CAGAAATAAATCCAACAGGG-3' }\end{array}$ & 228 & 54 \\
\hline 4 & $\begin{array}{l}\text { SIP-Ex4-f } \\
\text { SIP-Ex4-r }\end{array}$ & $\begin{array}{l}\text { 5'-AGATGGTTACAATTTTGTGC-3' } \\
\text { 5'-GCAAGTGAATCTITAACGAC-3' }\end{array}$ & 182 & 54 \\
\hline 5 & $\begin{array}{l}\text { SIP-Ex5-f } \\
\text { SIP-Ex5-r }\end{array}$ & $\begin{array}{l}\text { 5'-GATTCTCCCCATAACTGGC-3' } \\
\text { 5'-CAGGGTAGAGTTTGCTGACC-3' }\end{array}$ & 337 & 56 \\
\hline 6 & $\begin{array}{l}\text { SIP-Ex6-f } \\
\text { SIP-Ex6-r }\end{array}$ & $\begin{array}{l}\text { 5'AGTAGTTTCCGGAATGTCTC-3' } \\
\text { 5'-AGCATGAGCTCTGGAGTTAG-3' }\end{array}$ & 500 & 56 \\
\hline 7 & $\begin{array}{l}\text { SIP-Ex7-f } \\
\text { SIP-Ex7-r }\end{array}$ & $\begin{array}{l}\text { 5'-AGCATGAGCTCTGGAGTTAG-3' } \\
\text { 5'-GTATATGTGGCCCACAGTTG-3' }\end{array}$ & 269 & 54 \\
\hline 8 & $\begin{array}{l}\text { SIP-Ex8-f } \\
\text { SIP-Ex8-r }\end{array}$ & $\begin{array}{l}\text { 5'-AGGCTITCTTGTCTATACCC-3' } \\
\text { 5'-AGGCTTTCTTGTCTATACCC-3' }\end{array}$ & 328 & 56 \\
\hline 9 & $\begin{array}{l}\text { SIP-EX9-f } \\
\text { SIP-Ex9-r }\end{array}$ & $\begin{array}{l}\text { 5'-TCTCTGCTIITCTITGAGG-3' } \\
\text { 5'-GACTGAGGTGGGAGGATTG-3' }\end{array}$ & 423 & 56 \\
\hline 10 & $\begin{array}{l}\text { SIP-Ex10-f } \\
\text { SIP-Ex10-r }\end{array}$ & $\begin{array}{l}\text { 5'-TGGCAGTCCTACACATACTC-3' } \\
\text { 5'-GAGTTAGGCTGCCTTCATG-3' }\end{array}$ & 453 & 56 \\
\hline
\end{tabular}




\section{Fluorescence in situ hybridisation (FISH)}

FISH was carried out according to standard protocols as previously described. ${ }^{28}$ The detection of biotinylated probe was performed by a FITC-avidin system leading to light signals. ${ }^{29}$ Slides were evaluated on a Zeiss Axioplan fluorescence microscope. Fifteen metaphases were taken into account to determine the localisation.

\section{Results}

\section{Chromosomal location and genomic structure of SIP1}

The SIP1 gene was assigned to the chromosomal region $14 q 13-q 21$ by FISH analysis (Figure1) using BAC clone B869G2 (CEPHB751M03476Q3) which contains the entire SIP1 gene. The location was further confirmed by using DNA of the chromosome14 specific somatic cell hybrid GM 10479 (kindly provided by Dr N Spurr) for PCR with SIP1specific primers (Table 1 ).

BAC B869G2 was used to determine the complete exonintron structure of the SIP1 gene. Exons were identified by designing primers starting from the $5^{\prime}$ and $3^{\prime}$ end of the CDNA and comparing the genomic with the cDNA sequence. After identification of the first and last exon, primers were designed from the SIP1 cDNA sequence flanking these exons in order to determine the sequence of the adjacent exons. By using this strategy we quickly identified the complete exonintron structure of SIP1 which encompasses 10 exons (Table2). The sequences are deposited in Genbank under accession numbers AJ250932-AJ250939.

PCR of SIP1 CDNA obtained from RNA of EBV-tran sformed lymphoblastoid cell lines from control individuals revealed, in addition to a strong PCR product representing the fulllength transcript, four faint fragments corresponding to alternatively spliced transcripts of exons 6, 7, 8, and 7 and 8, respectively as shown by sequencing of each cloned PCR fragment (Figure2). An identical transcription pattern was also obtained from RNA of fresh blood (data not shown).

\section{Molecular genetic analysis of SIP1 in SMA patients}

About $4-5 \%$ of SMA patients with an undistinguishable phenotype from autosomal recessive 5q13-linked SMA do not show any mutation within the SMN 1 gene and carry two SMN 1 copies, suggesting that these patients have 5q13-unlinked SMA. ${ }^{11}$

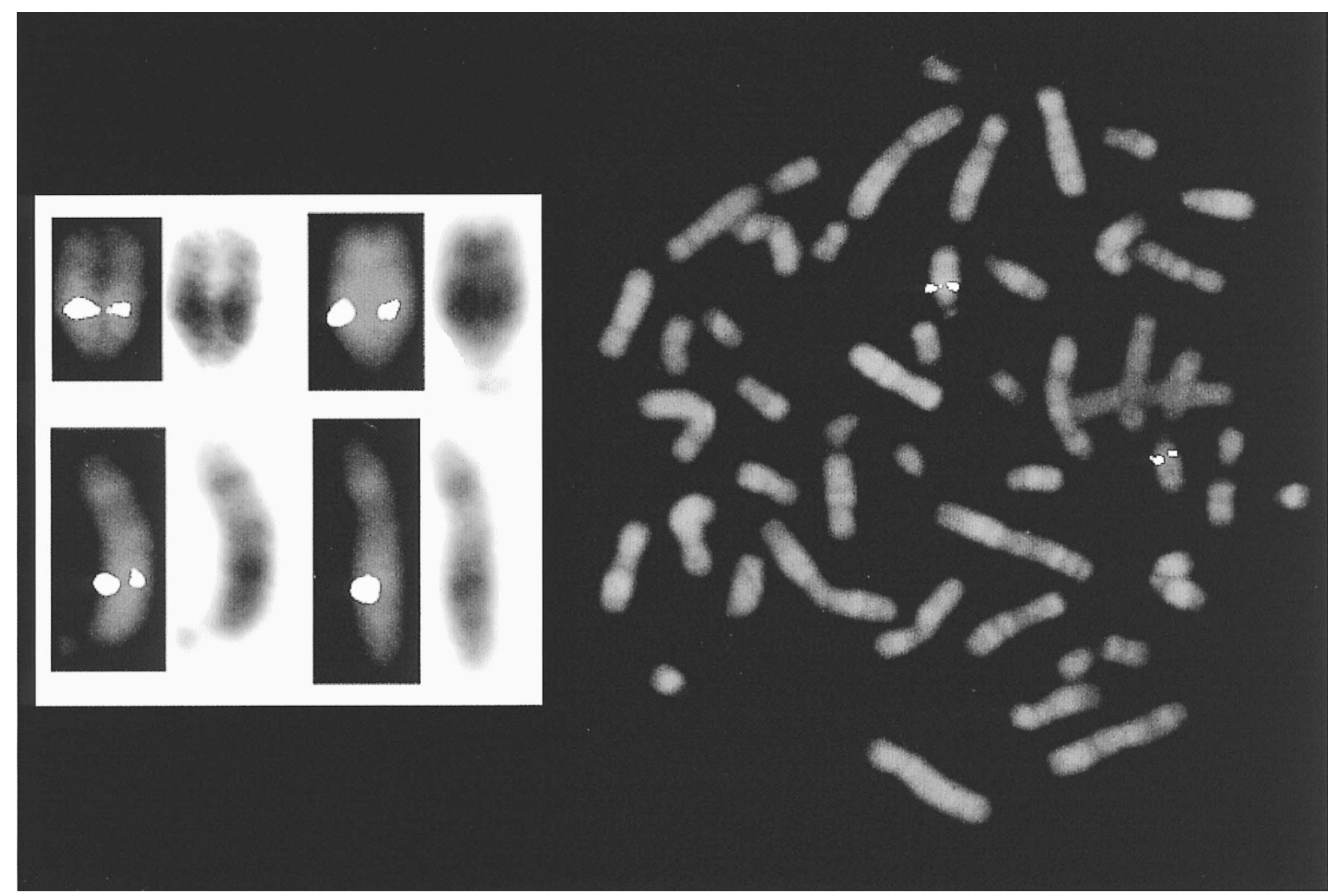

Figure 1 Metaphase and single selected chromosomes showing result of fluorescence in situ hybridisation (FISH) using the specific BAC clone B869G2 which covers the complete SIP1 gene. SIP1 was assigned to the chromosomal region 14q13-q12. For comparison the GTG-banding of the chromosomes is also shown. The images were captured with the ISIS digital FISH imaging system (MetaSystems, Altlussheim, Germany) using a XC77 CCD camera with on-chip integration (Sony). 
Table 2 Exon-intron organisation of SIP1

\begin{tabular}{crllll}
\hline & $\begin{array}{l}\text { Exon } \\
\text { size } \\
\text { Exon }\end{array}$ & $\begin{array}{l}\text { cDNA } \\
\text { (bp) }\end{array}$ & $\begin{array}{l}\text { 5' splice } \\
\text { position }^{\text {donor }}\end{array}$ & Intron & $\begin{array}{l}\text { 3' splice } \\
\text { acceptor }\end{array}$ \\
\hline 1 & 136 & $117-253$ & GGTCCAgtgagt & 1 & ttgtagGATCGA \\
2 & 85 & $254-338$ & ATTCTgtgagt & 2 & ctctagCTTCA \\
3 & 90 & $339-428$ & CGACAGgtaagt & 3 & ctttagAATGTG \\
4 & 59 & $429-487$ & GACAATgtgagt & 4 & ctttaGCCAAA \\
5 & 115 & $488-602$ & ATACAAgtaagg & 5 & ttcagATTGGT \\
6 & 45 & $603-647$ & AATCAGgtaaaa & 6 & tttagGCAACA \\
7 & 69 & $648-716$ & GAATTGgtagta & 7 & ttttagGGAAGA \\
8 & 111 & $717-827$ & TTAGTGgtaagt & 8 & tttagGATAGC \\
9 & 59 & $828-886$ & TAGCAGgtatag & 9 & tactagGTATT \\
10 & 37 & $887-923$ & & & \\
\hline
\end{tabular}

axonic sequences are given in capital letters, intronic sequences in small letters.

The SIP1 gene was analysed in 23 typical SMA patients who carry two SMN1 copies and no mutation in SMN1 and were considered 5q-unlinked SMAs. We performed direct sequencing of either RT-PCR products that cover the complete SIP1 coding region or genomic $P C R$ products that encompass each exon by using intronic flanking primers (Table 1). No mutation and no polymorphism within the coding region or the exon-intron boundaries, and no aberrant transcripts were identified.

Furthermore, we analysed 26 sibs belonging to 11 SMA families who display identical 5q13 haplotypes and identical SM N 1 mutations on both chromosomes but variable phenotypes (unaffected and affected, typell and III or typellla and IIIb, respectively, see Materials and Methods) and addressed the question whether SIP1 could be a modifier gene for SM A phenotypic variability. We looked for DNA sequence variances by sequencing the complete coding region either from RT-PCR products or genomic fragments and for transcription differences by semi-quantitative analysis of RT-PCR products of the 5 isoforms (Figure3). No mutation, polymorphism or transcription variance among sibs with variable phenotype was identified. We concluded that neither the phenotypic variability nor the $5 q 13$-unlinked SMA is caused by mutations or transcription differences within SIP1.

\section{Discussion}

The fact that about $4-5 \%$ of SMA patients reveal no mutation within SMN 1 but show SMA-like phenotype on one hand and the intrafamilial variability among SMN 1 detected sibs on the other is rather striking and prompted us to search for the molecular cause of these phenomena. The intrafamilial variability is especially interesting since the milder affected sibs or the unaffected SMN1 deleted sibs are in most cases females. ${ }^{5-8,11}$ The discovery of the modifying factor that prevents these individuals from developing SM A might be of therapeutic relevance.

Since the number of SMA patients showing phenotypic variability or those which are $5 q$-unlinked is very small, linkage analysis is not suitable. Two strategies can be applied in such cases (a) the candidate approach, eg searching for mutations and expression differences within SMN interacting proteins, which we have chosen in our study, and (b) SMA animal models. Since the knock-out SMN mouse was embryonically lethal ${ }^{30}$ and no transgenic SMA animals were available, only the first strategy could be applied. However, during the review process of this paper two groups reported the creation of SMA transgenic mice by introduction of the human SMN2 gene into the $\mathrm{Smn}^{-1-}$ background. ${ }^{31,32}$ These will open new possibilities of identifying modifying genes in future. Muscular dystrophies are a good example of similar phenotypes caused by mutations in various interacting proteins belonging to the same pathway and protein complex. ${ }^{33}$ By using the second strategy, the animal model, Tsiu's group has successfully identified a modifying gene for $\mathrm{CF}^{34}$

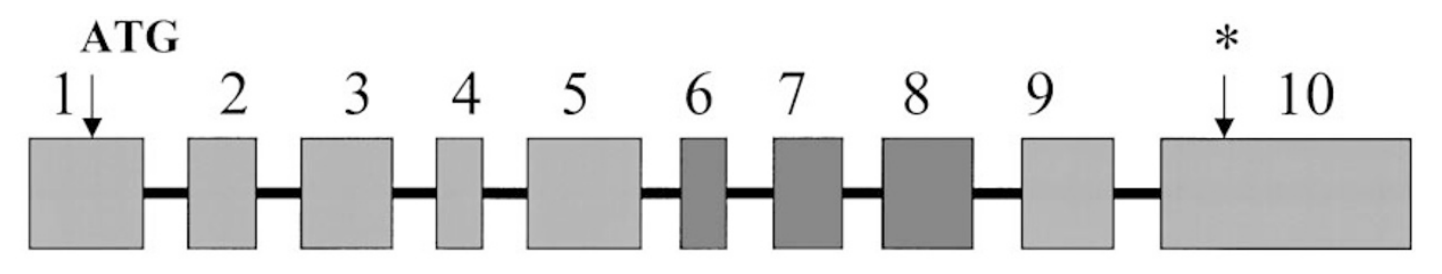

\section{Alternatively spliced transcripts}

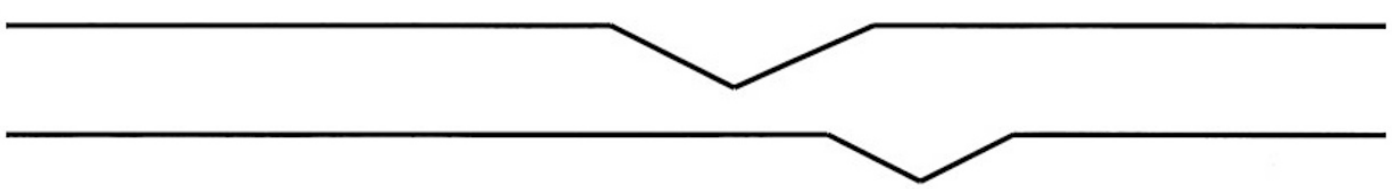

Figure 2 Schematic representation of the exon-intron structure of SIP1 and the alternatively spliced transcripts. 


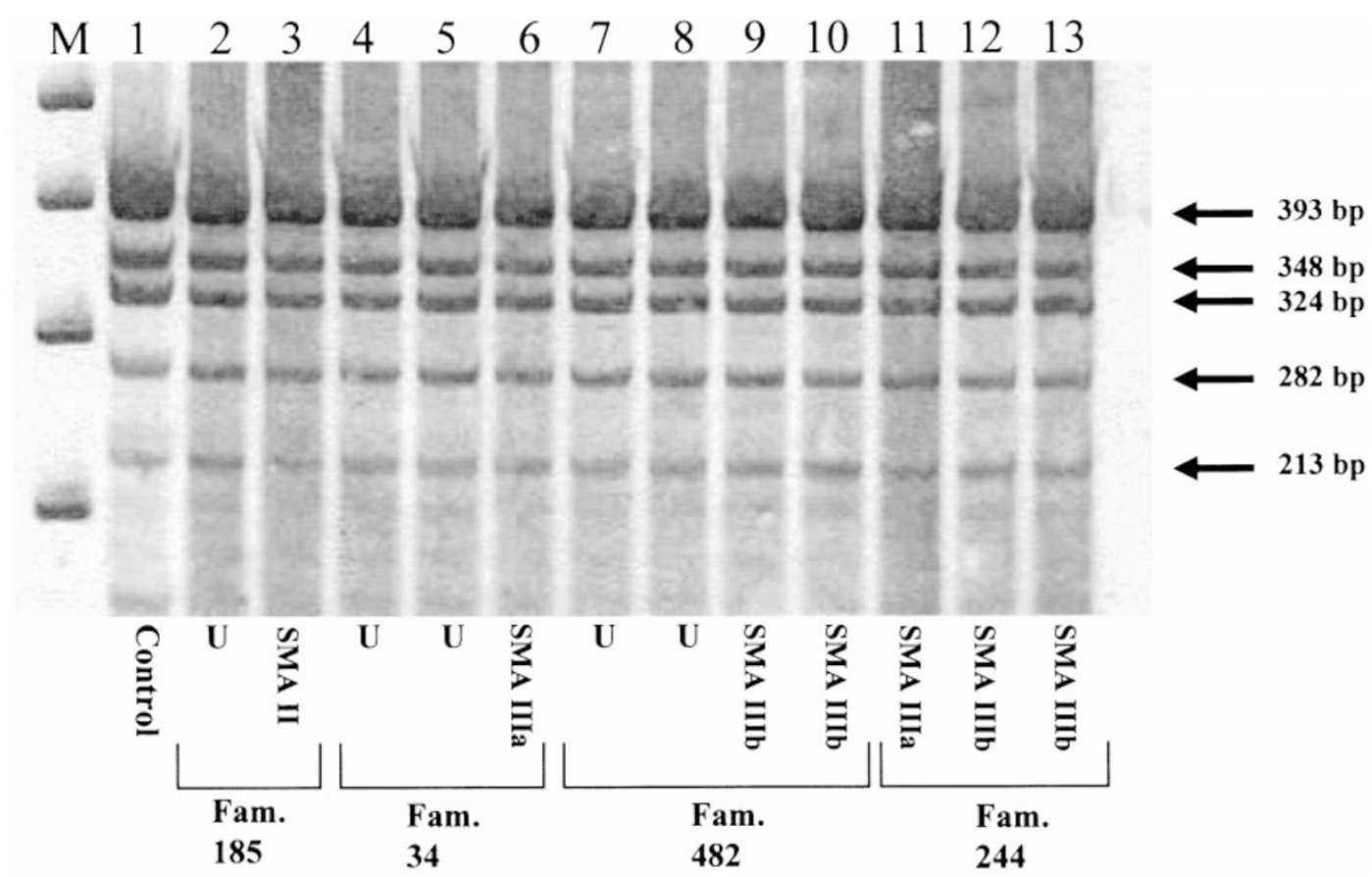

Figure 3 Quantitative analysis of RT-PCR products of SIP1 amplified with specific primers localised in exons5 and 9 from four SMA families with sibs showing all homozygous absence of SM N1 but variable phenotypes (unaffected and affected or typellla and IIIb SMA). The five isoforms are marked with arrows. $U$ = unaffected sib, $M=100$ bp ladder (Life Technology).

Although SIP1 and SMN are closely interacting proteins, part of the same protein complex, the same pathway and exhibit the same cellular location in gems and the cytoplasm, our data suggests that SIP1 is neither responsible for 5q-unlinked SMA nor for the phenotypic variability observed in SM A families. Recently a strong interaction between SMN and a neuron specific profilin, PFNII, which is a microfilament-associated protein has been reported. ${ }^{35}$ This also suggests that SMN may have other functions than in SnRNP biogenesis and premRNA splicing, and that its as yet unknown function may be responsible for the selective degeneration of the motor neurons in the spinal cord. Therefore, other SMN interacting proteins, like PFNII, or RNAs have to be analysed as potential SMA modifiers. Furthermore, the availability of SMA transgenic animals will open new possibilities in future.

\section{Electronic database information}

Accession numbers for SIP1 exons and intronic flanking sequences are from AJ250932 to AJ250939.

Online Mendelian Inheritance in Man (OMIM), http:// www.ncbi.nlm.nih.nih.gov/Omim (for typel SMA [WerdnigHoffman disease: MIM 253300], type II SMA [MIM 253550], and type III SMA [Kugelberg-Welander disease: MIM 253400]), SIP1 [MIM602595], SM N1 [MIM 600354] and SMN2 [MIM603519]

\section{Acknowledgements}

We are grateful to $\mathrm{H}$ Raschke and $\mathrm{S}$ Reader for excellent technical assistance, and to RZPD for making the BAC clones available. This work was supported by the Deutsche Forschungsgemeinschaft.

\section{References}

1 Pearn J: Classification of spinal muscular atrophies. Lancet 1980; 1: $919-922$.

2 Ludvigsson P, Olafsson E, Hauser WA: Spinal muscular atrophy. Incidence in Iceland. Neuroepidemiology 1999; 18: 265-269.

3 Munsat T, Davies KE: Meeting report: International SMA Consortium Meeting. Neuromusc Disord 1992; 2: 423-428.

4 Rudnik-Schöneborn S, Röhrig D, Morgan G, Wirth B, Zerres K: Autosomal recessive proximal spinal muscular atrophy in $101 \mathrm{sibs}$ out of 48families: clinical picture, influence of gender, and genetic implications. Am J Med Genet 1994; 51: 70-76.

5 Cobben JM, Steege van der G, Grootscholten P, de Visser M, Scheffer H, Buys CHCM : Deletions of the survival motor neuron gene in unaffected siblings of patients with spinal muscular atrophy. Am J Hum Genet 1995; 57: 805-808.

6 Hahnen E, Forkert R, Marke C et al: Molecular analysis of candidate genes on chromosome $5 q 13$ in autosomal recessive spinal muscular atrophy: evidence of deletions of the SMN gene in unaffected individuals. Hum Mol Genet 1995; 4: 1927-1933.

7 Wang $\mathrm{CH}, \mathrm{Xu}$ J, Carter TA et al: Characterization of survival motor neuron (SM Nt) gene deletions in asymptomatic carriers of spinal muscular atrophy. Hum Mol Genet 1996; 5: 359-365.

8 Brahe C, Zappata S: Presymptomatic diagnosis of spinal muscular atrophy (SMA) III confirmed by deletion analysis of survival motor neuron gene. Am J Med Genet 1995; 59: 101-102.

9 Lefebvre S, Bürglen L, Reboullet $S$ et al: Identification and characterization of the spinal muscular atrophy determining gene. Cell 1995; 80: 155-165. 
10 Wirth B: An update of the mutation spectrum of the survival motor neuron gene (SMN1) in autosomal recessive spinal muscular atrophy (SMA). Hum Mutat 2000; 15: 228-237.

11 Wirth B, Herz M, Wetter A et al: Quantitative analysis of survival motor neuron copies: Identification of subtle SMN1 mutations in patients with spinal muscular atrophy, genotype-phenotype correlation, and implication for genetic counseling. Am J Hum Genet 1999; 64: 1340-1356.

12 Burghes AHM: When is a deletion not a deletion? When it is converted. Am J Hum Genet 1997; 61: 9-15.

13 Campbell L, Potter A, Ignatius J, Dubowitz V, Davies K: Genomic variation and gene conversion in spinal muscular atrophy: implications for disease process and clinical phenotypes. Am J Hum Genet 1997; 61: 40-50.

14 MCAndrew PE, Parsons DW, Simard LR et al: Identification of proximal spinal muscular atrophy carriers and patients by analysis of SMNt and SMNc gene copy number. Am J Hum Genet 1997; 60: 1411-1422.

15 Lorson CL, Hahnen E, Androphy EJ, Wirth B: A single nucleotide in the SMN gene regulates splicing and is responsible for spinal muscular atrophy. Proc Natl Acad Sci USA 1999; 96: 6307-6311.

16 Monani UR, Lorson CL, Parsons DW et al: A single nucleotide difference that alters splicing patterns distinguishes the SMA gene SMN1 from the copy gene SMN2. Hum Mol Genet 1999; 8: 1177-1183.

17 Gennarelli M, Lucarelli M, Capon F et al: Survival motor neuron gene transcript analysis in muscles from spinal muscular atrophy patients. Biochem Biophys Res Commun 1995; 213: 342-348.

18 Lorson CL, Strasswimmer J, Yao L-M et al: SMN oligomerization defect correlates with spinal muscular atrophy severity. Nat Genet 1998; 19: 63-67.

19 Liu Q, Dreyfuss G: A novel nuclear structure containing the survival of motor neuron protein. EMBO J 1996; 15: 3555-3565.

20 Fischer U, Liu Q, Dreyfuss G: The SMN-SIP1 complex has an essential role in spliceosomal snRNP biogenesis. Cell 1997; 90: 1023-1029.

21 Liu Q, Fischer U, Wang F, Dreyfuss G: The spinal muscular atrophy disease gene product, SMN, and its associated protein SIP1 are in a complex with spliceosomal snRNP proteins. Cell 1997; 90: 1013-1021.

22 Pellizzoni L, Kataoka N, Charroux B, Dreyfuss G: A novel function for SMN, the spinal muscular atrophy disease gene product, in pre-mRNA splicing. Cell 1998; 95: 615-624.

23 Zerres K, Rudnik-Schöneborn S: Natural history in proximal spinal muscular atrophy (SMA): clinical analysis of 445 patients and suggestions for a modification of existing classifications. Arch Neurol 1995; 52: 518-523.
24 Miller SA, Dykes DD, Polesky HF: A simple salting out procedure for extracting DNA from human nucleated cells. Nucleic Acids Res 1999; 3: 1215.

25 DiDonato CJ, Morgan K, Carpten JD et al: Association between Ag1-CA alleles and severity of autosomal recessive proximal spinal muscular atrophy. Am J Hum Genet 1994; 55: 1218-1229.

26 Melki J, Lefebvre S, Burglen L et al: De novo and inherited deletions of the $5 q 13$ region in spinal muscular atrophies. Science 1994; 264: 1474-1477.

27 Wirth B, Hahnen E, Morgan K et al: Allelic association and deletions in autosomal recessive proximal spinal muscular atrophy: Association of marker genotype to disease severity and candidate cDNAs. Hum Mol Genet 1995; 4: 1273-1284.

28 Deimling von F, Scharf J, Liehr T et al: Human and mouse RAD17 genes: Identification, localization, genomic structure and histological expression pattern in normal testis and seminoma. Hum Genet 1999; 105: 17-27.

29 Liehr T, Thoma K, Kammler $\mathrm{K}$ et al: Direct preparation of uncultured EDTA-treated or heparinized blood for interphase FISH analysis. Appl Cytogenet 1995; 21: 185-188.

30 Schrank B, Gotz R, Gunnersen JM et al: Inactivation of the survival motor neuron gene, a candidate gene for human spinal muscular atrophy, leads to massive cell death in early mouse embryos. Proc Natl Acad Sci USA 1997; 94: 9920-9925.

31 Hsieh-Li HM, Chang JG, Yong YJ et al: A mouse model for spinal muscular atrophy. Nat Genet 2000; 24: 66-70.

32 Monani UR, Sendtner M, Coovert DD et al: The human centromeric survival motor neuron gene (SMN2) rescues embryonic lethality in $\mathrm{SMN}^{-1-}$ mice and results in a mouse with spinal muscular atrophy. Hum Mol Genet 2000; 9: 333-339.

33 Campbell KP: Three muscular distropies: Loss of cytoskeletionextracellular matrix linkage. Cell 1995; 80: 675-679.

34 Rozmahel R, Wilschanski M, Matin A et al: Modulation of disease severity in cystic fibrosis transmembrane conductance regulator deficient mice by a secondary genetic factor. Nat Genet 1996; 12: 280-287.

35 Gieseman T, Rathke-Hartlieb S, Rothkegel $M$ et al: A role for polyproline motifs in spinal muscular atrophy protein SMN. J Biol Chem 1999; 32: 37908-37914. 